\title{
Surveillance and clinical outcome of bosniak IIF renal cysts: a mini review
}

\begin{abstract}
Bosniak was the normal radiological assessment procedure for cystic renal lesions. Originally, it relied on computed tomography (CT) scan results and subsequently extended to magnetic resonance imaging (MRI). Renal cell carcinoma (RCC) surveillance was not enhanced in the past 20 years. Bosniak classifications depend on different morphological modifications in renal cysts such as septa development, wall thickening of nodal elements, wall and/or septa calcification, hyperdense cystic composition and contrast enhancement following intravenous contrast injection. Bosniak group comprised four categories, I and II lesions normally benign, Group III possibly malignant and IV mostly malignant. Recently, Category IIF (BIIF) was added, including cysts that cannot be easily differentiated from either Class II or III. The aim of this study was to investigate the surveillance and clinical outcome of Bosniak IIF renal cysts. We searched for retrospective evidence of Bosniak IIF renal cysts, cystic renal lesions, Bosniak IIF lesions, Carcinomas, Renal Cell, and Malignant Neoplasms obtainable up to April 2019. We selected articles published in English. The following databases were searched; PubMed and Google Scholar. The discovery of Bosniak Category IIF is considered as a successful method in renal cyst diagnosis and treatment possibly resulting in nephron-sparing during complicated renal cyst care.
\end{abstract}

Volume 8 Issue | - 2020

\author{
Abdalla Ali Deb,' Chidiebere Emmanuel \\ Okechukwu, ${ }^{2}$ Shady Emara, ${ }^{3}$ Sami A.Abbas ${ }^{4}$ \\ 'Locum Consultant Urologist in NHS - UK \\ ${ }^{2}$ Physical activity and health promotion, Department of \\ Biomedicine and prevention, Faculty of Medicine and Surgery, \\ University of Rome Tor vergata, Via Montpellier, Italy \\ ${ }^{3}$ Urology Fellow, Western General Hospital UK \\ ${ }^{4}$ Consultant Urologist; National Institute of Urology and \\ Nephrology; Cairo, Egypt
}

Correspondence: Abdalla Ali Deb, Locum Consultant Urologist in NHS - UK, Email drabdodeeb@hotmail.com

Received: December 06, 2019 | Published: January 21, 2020

Keywords: kidney neoplasms, carcinoma, bosniak classification

Abbreviations: MRI, magnetic resonance imaging; CT, computed tomography; RCC, renal cell carcinoma; PRISMA, recommended reporting items for systematic reviews and metaanalyses

\section{Introduction}

In the past, renal cyst masses were either classified as simple cysts or complicated cysts. In 1986, ${ }^{1}$ Bosniak classifications were adopted and revised many times, most significantly in $2005 .{ }^{2}$ It was used as an effective method to determine renal cystic masses. It has been widely recognized and used by various radiologists and urologists, based on general agreement between experts for a long time. ${ }^{3}$ The Bosniak classification system uses many anatomical changes in renal cysts which are septa growth, nodal wall thickening, wall calcification as well as septa, hyperdense cystic material and intravenous infusion enhancement. Kidney cystic lesions were classified into four computed tomography (CT) classifications. Class I and II are considered benign, Class III moderately dangerous and IV mainly cancerous. Therefore, Classification IIF (BIIF) was provided for those cysts that cannot be classified as Class II or III and need follow-up scanning. ${ }^{4-11}$ Previous studies on long-term category IIF follow-up, III, and IV lesions have focused on malignancy rates and Histological structure when established. ${ }^{12,13,14}$ Several authors have reported results following treatment, based on local recurrence and cancer-specific survival. ${ }^{14-17}$ The aim of this study was to assess the ratio of tiny $(<4 \mathrm{~cm})$ Bosnian lesions classes IIF, III and IV that advance, decline or stay unchanged during effective close observation and their clinical outcomes.

\section{Methods}

\section{Search strategy}

We identified studies that reported on Bosniak IIF renal cyst monitoring, Bosniak IIF lesions, kidney cyst, malignant cystic lesions and renal cell carcinomas obtainable up to April 2019. We preferred articles published in English. We looked for reports that included Bosniak IIF Renal Cyst Surveillance, Bosniak IIF Lesions, renal cysts, malignant cystic lesions and renal cell Carcinoma.

\section{Types of studies}

Original articles, meta-analyses and systematic review.

\section{Inclusion and exclusion criteria}

We reviewed specific articles based on recognition of Bosniak IIF renal cyst, Bosniak IIF lesions, renal cyst, malignant cystic lesions, and renal cell carcinoma. Unrelated papers were excluded.

\section{Data extraction and management}

We selected research from the databases. We checked significance based on one or more of the following MeSH keywords; Kidney Neoplasms, Carcinoma, Bosniak grouping. We gathered copies of all the papers listed as potentially relevant and made exclusions dependent on historical debate and repeated publications. A Recommended Reporting Items for Systematic Reviews and MetaAnalyses (PRISMA) flow diagram (Figure 1) clarified the selection process. 


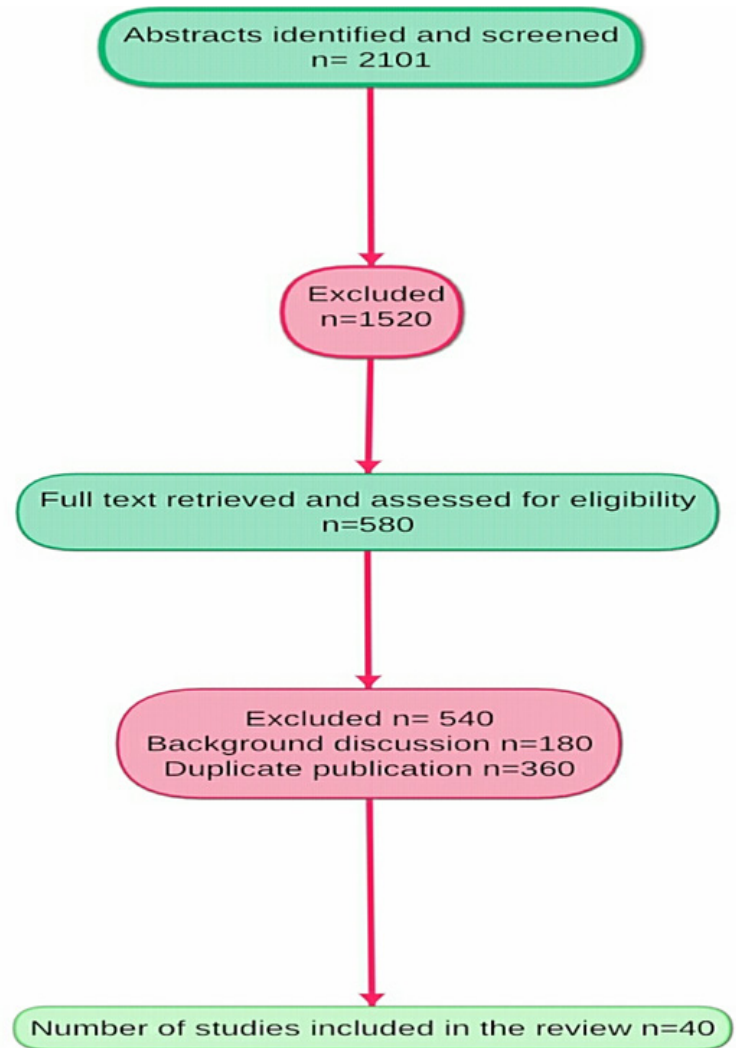

Figure I Preferred Reporting Items for Systematic Reviews and Metaanalyses (PRISMA) flow diagram.

\section{Surveillance of bosniak IIF renal cysts}

The three factors affecting the occurrence of malignant changes in Bosniak IIF are:

I. Absence of initial observation period and subsequent operation following diagnosis, which eliminates the possibility of showing overtime of balanced and harmless origin,

\section{Patients and surgeon urge for surgery}

III. Inter-observer variation in Bosniak classification. In most other instances, intensive surveillance intervention was the primary line for Bosniak Category IIF control, while surgical excision was seen for younger patients or those who fear renal cell carcinoma and its consequences. ${ }^{11}$

Bosniak IIF renal cysts are often screened until its usually integral. A small group of Bosniak IIF renal cysts are difficult to screen, an attribute linked to increased malignancy in surgical morphology. ${ }^{4,10,18}$ Several findings suggest that Bosnian Class III lesions are "surgical lesions" because the rate of carcinoma is around $50 \%$. RCCs are often low-stage and low-grade tumors that follow this process. ${ }^{17,19}$ Based on studies that investigated the diagnosis, pathology and findings of Bosniak Type IIF and III cystic lesions, it was confirmed that approximately $30 \%$ of Bosniak IIF cysts are at risk of malignancy; consequently, prolonged monitoring for close to 5 years should be the standard form of treatment. ${ }^{20}$ Progressive Bosniak IIF lesions may be excised surgically. This technique contributed to a wide range of malignant obliteration, most of which remained low-stage and lowgrade RCCs. ${ }^{20}$ Bosniak III lesions are extremely malignant and can be treated as solid renal tumours under current recommendations. ${ }^{21,22}$ Imaging procedures on Bosniak IIF lesions fluctuates, depending largely on urologists and radiologists ' comprehension. Bosniak recommended the first CT take-up, a half-year after evaluation. If the lesion doesn't improve, assessment should be done periodically. ${ }^{4} \mathrm{Cyst}$ growth criteria are debatable, Gabr et al. ${ }^{8}$ reported that RCC duration is not based on progress overtime, but on internal architecture and improvement. Other groups later announced comparative information. 7,16 Complex progressive and non-progressive cysts of Bosniak IIF begin to grow independently. Though surgical intervention in lesions with sustained growth above $5 \mathrm{~mm}$ per year was recommended. ${ }^{8}$

\section{Clinical outcome of bosniak IIF renal cysts}

Bosniak IIF has many neoplasms, the most widely recognized malignant renal tumour was clear cell carcinoma, it represented fewer than $50 \%$ of malignant lesions. $4 \%-15 \%$ of all RCCs Shows cystic growth morphology. ${ }^{23}$ there are four examples of cystic growth morphology which are normal unilocular cystic growth, stereotypical multinodular cystic production, origins of a single cyst epithelium, or cystic necrosis. ${ }^{24}$ Few Class IIF follow-up series are available and none include a significant number of cases with MRI. ${ }^{4,7,25}$ within 13 percent lesions of IIF found in previous Bosniak series, 8 were laparoscopically resected and four of the other eight were malignant. ${ }^{16,25}$ Real cystic growth, not necrosis, suggests better prognosis. ${ }^{15}$ previous studies on Bosniak cysts concentrated on differentiating between malignant and benign lesions, and it did not explain carcinoma subtypes. It is incorrect to say that a malignant cystic lesion contributes to cystic-clear cell carcinoma and a mild cyst lesion is an epithelial cyst. However, a wide range of benign and malignant cystic renal neoplasms are present, including cystic clearly defined cell carcinoma, multilocular CRC, cystic nephroma and mixed epithelial and stromal tumours. Each has an alternate expectation and may need distinctive intervention. ${ }^{26-28}$

Smith et al. ${ }^{16}$ found a high incidence of malignancy in resected Bosniak IIF, however the volume of Bosniak IIF lesions resected was small and a population sub-set of Bosniak IIF lesions. The resected Bosniak IIF incidence among cohort of patients was selected in a unique way and had more malignant threats than the imaging population. $67 \%$ (two out of three) of Bosniak IIF in RCC patients are malignant. Such associations suggest that the malignancy risk of resected Bosniak IIF lesions in this case could not have been affected. ${ }^{16}$ In the Bosniak IIF (BIIF) group, the $12 \%$ malignancy incidence was time-consuming and until the diagnosis of BIIF lesions with radiological tools. Malignancy rates in BIII lesions increased from 51 to 61 percent in each Bosnian community since BIIF adoption, indicating that nearly 10 percent of the procedure can be avoided if this classification was implemented. Surprisingly, the malignancy risk in the BII classification remains unsatisfactorily elevated (12\%), even in the procedure reported after BIIF was incorporated..$^{29}$ The malignancy rate of $54 \%$ differs from the malignancy rate of $82 \%$ in 33 Bosniak III resections recorded by O'Malley et al. ${ }^{7}$ The high incidence of malignancy was because of the adoption of more established examinations.

Using the Bosniak IIF method, the precision of downgrading lesions were shown in the classification system, which were not complicated enough to be graded as category III, but complexed than category II lesions. ${ }^{4}$ Past history of primary renal malignancy, coexisting Bosniak IV cystic renal lesion and/or firm renal mass, and multiplicity of Bosniak III cystic renal lesions were all associated 
with increased risk of malignancy in cystic renal lesions in Bosniak IIF. ${ }^{16}$ Grade IIF cysts can be suggested for surgical removal, for example in young patients who do not want further follow-up trials. ${ }^{4}$ Nevertheless, not all patients require surgery. Many incidents of malignancy in progressive groups are low-stage renal cell carcinoma. Such carcinomas' prognosis is adequate compared to other renal malignancies due to the low metastatic frequency. ${ }^{30-33}$ Hence, early detection of several malignancies had no severe consequences or adverse effect on the patients. Among elderly patients in poor physical health, follow-up examination is suggested instead of intervention. Frequent follow-up is inadequate among young patients. ${ }^{25}$

\section{Follow-up imaging for bosniak IIF lesions}

Imaging assessments of how Category $2 \mathrm{~F}$ cyst progressed depends on whether enhanced stable tumour sections have occurred or on the length, quantity or variability of enhanced septa or thickness of the enhanced surface lesion. ${ }^{34}$ Depending on the unusual malignancy of Bosniak IIF renal cysts, the American College of Radiology (ACR) recommended that CT or MRI exams, should be conducted without IV contrast at 6-12 months, following diagnosis for a period of five years. The aim of imaging surveillance is to detect Bosniak IIF renal cysts that progress to higher class lesions, because higher reclassification is linked to higher class lesions. ${ }^{29}$ Suggested BIIF follow-up standards vary in various studies. A multiphase contrast $\mathrm{CT}$ is required to detect potential movement. Morton Bosniak suggested a primary CT check after half a year, and if the lesion remained unchanged, a CT examination should be conducted annually for at least 5 years. ${ }^{4}$ Several researchers recommend identical CT scans after 3, 6, and 12 months. Bosniak IIF lesions change presentation based on the: (I) severity of BIIF lesions with limited results comparable to Category II and (II) multi-faceted BIIF lesions closer to Class III. Morton Bosniak later indicated that BIIF cysts with mild effects should only follow-up for 1-2 years, whereas progressively complicated BIIF cysts could be studied for a longer period (e.g. 3-4 years or longer). ${ }^{34} \mathrm{CT}$ has the best level of accuracy to identify broad renal cystic volumes. For BIIF indications, early transition to MRI / Contrast Enhanced Ultrasound (CEUS) with a standardized procedure is widely used in different clinical settings after CT analysis, long-term progress of such a technique can affect clinical practice in the future, and will offer an effective and thorough treatment of Bosniak lesions. ${ }^{35}$ Biopsy of mildly difficult kidney cystic masses came into focus late and the trend seems to be more advanced, presumably to maintain the tracking of near BIII and BIIF lesions, due to the possibility of using local nephron-sparing operation (cryo / radiofrequency therapy ablation and/or laparoscopic resection) ${ }^{36-39}$ Nevertheless, intensive surveillance was found to be more cost-effective than nephron-sparing surgery among patients with Bosniak IIF renal cyst. ${ }^{40}$

\section{Conclusion}

Introducing Bosniak Category IIF appears to be promising, possibly creating a general nephron-sparing method to tackle complicated renal cysts. Even though a consistent follow-up period is difficult to determine, due to the variable development time. Few Bosniak IIF class are hazardous and tumors of low-stage and low grade. Nevertheless, intensive surveillance is the best way for monitoring the progress of Bosniak Class IIF cases.

\section{Acknowledgments}

None.

\section{Conflicts of interest}

The author declares there is no conflict of interest.

\section{References}

1. Bosniak MA. The current radiological approach to renal cysts. Radiology. 1986;158(1):1-10.

2. Israel GM, Bosniak MA. An update of the bosniak renal cyst classification system. Urology. 2005;66(3):484-488.

3. Koga S, Nishikido M, Inuzuka S, et al. An evaluation of bosniak's radiological classification of cystic renal masses. BJU Int 2000;86(6):607-609.

4. Israel GM, Bosniak MA. Follow-up ct of moderately complex cystic lesions of the kidney (bosniak category iif). Am J Roentgenol. 2003;181(3):627-633.

5. Spaliviero M, Herts BR, Magi-Galluzzi C, et al. Laparoscopic partial nephrectomy for cystic masses. J Urol. 2005;174(2):614-619.

6. Quaia E, Bertolotto M, Cioffi V, et al. Comparison of contrast-enhanced sonography with unenhanced sonography and contrast-enhanced ct in the diagnosis of malignancy in complex cystic renal masses. Am J Roentgenol. 2008;191(4):1239-1249.

7. O'malley RL, Godoy G, Hecht EM, et al. Bosniak category iif designation and surgery for complex renal cysts. J Urol. 2009;182(3):1091-1095.

8. Gabr AH, Gdor Y, Roberts WW, Wolf Jr JS. Radiographic surveillance of minimally and moderately complex renal cysts. BJU Int. 2009;103(8):1116-1119.

9. Song C, Min GE, Song K, et al. Differential diagnosis of complex cystic renal mass using multiphase computerized tomography. $J$ Urol. 2009;181(6):2446-2450

10. Kim DY, Kim JK, Min GE, et al. Malignant renal cysts: Diagnostic performance and strong predictors at mdct. Acta Radiol. 2010;51(5):590 598

11. Weibl P, Klatte T, Kollarik B, et al. Interpersonal variability and present diagnostic dilemmas in bosniak classification system. Scand J Uro Nephrol. 2011;45(4):239-244.

12. Hindman NM, Hecht EM, Bosniak MA. Follow-up for bosniak category 2f cystic renal lesions. Radiology. 2014;272(3):757-766.

13. Mousessian PN, Yamauchi FI, Mussi TC, et al. Malignancy rate, histologic grade, and progression of bosniak category iii and iv complex renal cystic lesions. Am J Roentgenol. 2017;209(6):1285-1290.

14. Schoots IG, Zaccai K, Hunink MG, et al. Bosniak classification for complex renal cysts reevaluated: A systematic review. J Urol. 2017;198(1):12-21.

15. Smith AD, Allen BC, Sanyal R, et al. Outcomes and complications related to the management of bosniak cystic renal lesions. Am J Roentgenol. 2015;204(5):W550-W556.

16. Smith AD, Remer EM, Cox KL, et al. Bosniak category iif and iii cystic renal lesions: Outcomes and associations. Radiology. 2012;262(1):152160

17. Park HS, Lee K, Moon KC. Determination of the cutoff value of the proportion of cystic change for prognostic stratification of clear cell renal cell carcinoma. J Urol. 2011;186(2):423-429.

18. Berland LL, Silverman SG, Gore RM, et al. Managing incidental findings on abdominal ct: White paper of the acr incidental findings committee. J Am Coll Radiol. 2010;7(10):754-773. 
19. Webster WS, Thompson RH, Cheville JC, et al. Surgical resection provides excellent outcomes for patients with cystic clear cell renal cell carcinoma. Urology. 2007;70(5):900-904.

20. Weibl P, Hora M, Kollarik B, Shariat SF, Klatte T. Management, pathology and outcomes of bosniak category iif and iii cystic renal lesions. World J Nephrol Urol. 2015;33(3):295-300.

21. Ljungberg B, Cowan NC, Hanbury DC, et al. Eau guidelines on rena cell carcinoma: The 2010 update. Eur Urol. 2010;58(3):398-406.

22. Campbell SC, Novick AC, Belldegrun A, et al. Guideline for management of the clinical t1 renal mass. J Urol. 2009;182(4):1271-1279.

23. Hartman DS, Davis Jr CJ, Johns T, et al. Cystic renal cell carcinoma. Urology. 1986;28:145-153.

24. Eble JN. Classification of tumours: Pathology and genetics of tumours of the urinary system and male genital organs. World Health Organization classification of tumours. 2004:255-257.

25. Hwang JH, Lee CK, Yu HS, et al. Clinical outcomes of bosniak category iif complex renal cysts in korean patients. Korean J Urol. 2012;53(6):386-390.

26. Cloix P, Martin X, Pangaud C, et al. Surgical management of complex renal cysts: A series of 32 cases. J Urol. 1996;156(1):28-30.

27. Siegel CL, McFarland EG, Brink JA, et al. Ct of cystic renal masses: Analysis of diagnostic performance and interobserver variation. Am J Roentgenol. 1997;169(3):813-818.

28. Curry NS, Cochran ST, Bissada NK. Cystic renal masses: Accurate bosniak classification requires adequate renal ct. Am J Roentgenol. 2000;175(2):339-342.

29. Graumann O, Osther SS, Karstoft J, et al. Evaluation of bosniak category iif complex renal cysts. Insights into imaging. 2013;4:471-480.

30. Bielsa O, Lloreta J, Gelabert-Mas A. Cystic renal cell carcinoma Pathological features, survival and implications for treatment. Br J Urol. 1998;82(1):16-20.
31. Smaldone MC, Uzzo RG. Active surveillance: A potential strategy for select patients with small renal masses. Future Oncol. 2011;7(10):11331147.

32. Eble JN, Bonsib SM. Extensively cystic renal neoplasms: Cystic nephroma, cystic partially differentiated nephroblastoma, multilocular cystic renal cell carcinoma, and cystic hamartoma of renal pelvis. Seminars in diagnostic pathology. 1998;15(1):2-20.

33. Murad T, Komaiko W, Oyasu R, et al. Multilocular cystic renal cell carcinoma. Am J Clin Patho. 1991;95(5):633-637.

34. Weibl P, Klatte T, Waldert M, et al. Complex renal cystic masses: Current standards and controversies. Int Urol Nephrol. 2012;44(1):13-18.

35. Bosniak MA. The bosniak renal cyst classification: 25 years later Radiology. 2012;262(3):781-785.

36. Agarwal MM, Hemal AK. Surgical management of renal cystic disease. Curr Urol reports. 2011;12(1):3-10.

37. Park BK, Kim CK, Lee HM. Image-guided radiofrequency ablation of bosniak category iii or iv cystic renal tumors: Initial clinical experience. Eur Radiol. 2008;18(7):1519-1525.

38. Harisinghani MG, Maher MM, Gervais DA, et al. Incidence of malignancy in complex cystic renal masses (bosniak category iii) Should imaging-guided biopsy precede surgery? Am J Roentgenol. $2003 ; 180(3): 755-758$

39. Lang EK, Macchia RJ, Gayle B, et al. Ct-guided biopsy of indeterminate renal cystic masses (bosniak 3 and 2f): Accuracy and impact on clinical management. Eur Radiol. 2002;12(10):2518-2524.

40. Andrew DS, Daniel C, Reza S, et al. Active Surveillance Versus Nephron-Sparing Surgery for a Bosniak IIF or III Renal Cyst: A CostEffectiveness Analysis. Am J Roentgenol. 2019;212(4):830-838. 